\title{
Analysis of qualitative and quantitative traits in seedlings of some crop field weeds (dicot) of Kaliachak-II Block of Malda district of West Bengal, India
}

\author{
P. Kamilya ${ }^{1,3}$, Sujit Das ${ }^{2}$, Ayan Das ${ }^{1}$ and Abhijit Sarkar ${ }^{2}$ \\ ${ }^{1}$ Department of Botany, Balurghat College, Balurghat, 733101, Dakshindinajpur, West Bengal, India \\ ${ }^{2}$ Laboratory of Applied Stress Biology, Department of Botany, University of Gour Banga, Malda, West \\ Bengal, India \\ ${ }^{3}$ Corresponding author, E-mail: pkamilya.in@gmail.com
}

[Received 16.08.2018; Revised 11.12.2018; Acceptance 25.12.2018; Published 31.12.2018]

\begin{abstract}
Qualitative and quantitative traits of seedlings of twenty crop field dicot weeds belonging to twelve families have been analysed. Major quantitative traits are considered for one way analysis of variance (ANOVA) using Duncan Multiple Range test to trace whether they show parallel behaviour or not with qualitative traits for distinction among the taxa. Cotyledonary Photosynthetic Index (CPI) shows negative correlation with seed mass of the weed taxa. Principal Component Analysis (PCA) shows partial dependence of qualitative and quantitative traits for artificial key construction supporting to analysis of variance(ANOVA).
\end{abstract}

Key words: Qualitative \& quantitative characters, Seedlings, Weeds

\section{INTRODUCTION}

Weeds are unwanted plants that interfere with healthy or normal growth and development of crops. These plants are also known to limit the yield of crops causing serious losses in the output of grains, seeds and fruits, etc. (Marwat et al. 2013). Most of the weeds display seeds and seedlings in crop fields within the very short periods in their life cycle. Therefore, rapid and accurate identification of weeds after evaluating their phenotypic traits at seedling stage might be an important step towards the designing of successful weed management program, which could save both time and money of farmers and reduces herbicide usage (Parkinson et al. 2013). Chomas et al. (2001) stressed on the identification of 54 common weeds at their seedling stage in the North Central States in view of successful weed management program.

Phenotypic traits of juvenile stages of plants have been analysed variously for their ecological adaptability and taxonomic perspectives (De Vogel 1980; Garwood 2009; Fogliani et al. 2009; Leck et al. 2008; Rodrigues \& Tozzi 2008; Tillich 2003; Zanne et al. 2005). Relationship between seed mass and size of different organs of seedlings have been variously demonstrated for their better adaptability in natural habitat (Zanne et al. 2005; Green \& Juniper 2004; Ibarra-Manriquez et al. 2001).

Besides there are many Indian workers (Naidu \& Shah 1978; Sampathkumar 1982; Deb \& Paria 1986; Kamilya \& Paria 1993, 1997; Paria \& Kamilya 1999; Paria et al. 2006; Das \& Kamilya 2014; Mukhopadhyay et al. 2013) who used the juvenile phenotypic traits to trace taxonomy, documentation and correlation. But statistical analysis for stability of traits 
for distinction among the taxa has not been attempted. Therefore, we have extracted both qualitative and quantitative data of seedling characters and performed different numerical analysis for strengthening the artificial key.

\section{MATERIALS AND METHODS}

In the present study we have given stress on the numerical analysis of different traits of seedlings as displayed in the artificial key. Cotyledon thickness has been measured at harvest with callipers. From this measure, (para)cotyledonary photosynthetic index (CPI) has been calculated as the inverse of (para)cotyledon thickness. The quantitative traits are tested through one way analysis of variance (ANOVA) using Duncan multiple range test (DMRT). All the statistical tests are performed using SPSS software (SPSS Inc., version 16.0). The entire data set of all qualitative and quantitative traits are subjected to Principal Component Analysis (PCA) using the Varimax method. This allows the identification of interrelated variables.

\section{RESULT AND DISCUSSION}

The character derrived through the morphological survey has been used to prepare an artificial dicotyledonous Key for the identification of 20 species of dicotyledonous seedlings under study. The Key as as follows:

1a. First two leaves alternate $\ldots \ldots \ldots \ldots \ldots \ldots \ldots \ldots \ldots \ldots \ldots \ldots . \ldots \ldots$

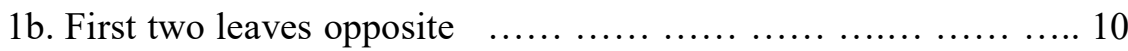

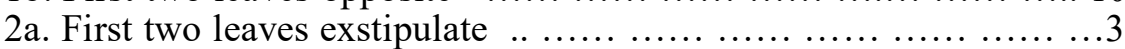

2b. First two leaves stipulate ............................... 7

3a. Apex of (para-)cotyledons retuse; first two leaves with five incomplete palmate lobes, venation actinodromous $\ldots . . . \ldots \ldots \ldots \ldots \ldots \ldots$........... Coccinia grandis

3b. (Para-)cotyledon apex otherwise; first two leaves ovate, veins camptodromous .. 4

4a. (Para-) cotyledons distinctly bilobed, venation actinodromous; base of first two

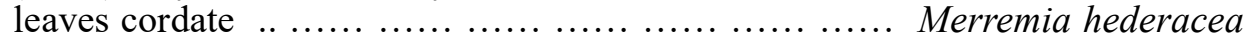

4b. (Para-) cotyledons not bilobed, venation hyphodromous; base of first two leaves oblique or cuneate ...5

5a. (Para-)cotyledons lanceolate, ventrally purplish; apex of first two leaves retuse ... 6

5b. (Para-) cotyledons ovate, ventrally not purplish; apex of first two leaves acute......

................................................................... Physalis angulata

6a. Axillary spines appear in later stages $\quad . . . . \ldots \ldots \ldots \ldots$......... Amaranthus spinosus

6b. Axillary pines do not appear in any stages ............... Amaranthus viridis

7a. Stipule ochreate . ................................. Rumex dentatus

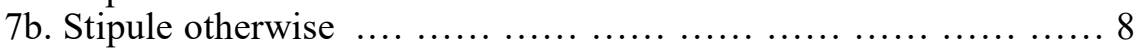

8a. (Para-) cotyledons comparatively smaller (3-4mm in length); first two leaves obovate, apex rounded $\ldots \ldots \ldots \ldots \ldots \ldots \ldots \ldots \ldots \ldots . \ldots \ldots$. Phyllanthus urinaria

8b. (Para-) cotyledons comparatively larger (3-4mm in length); first two leaves ovate or lanceolate, apex acute ............................... 9

9a. First two leaves lanceolate; subsequent leaves obscurely lobed; seedlings lack stellate hair ..................................... Chrozophora rottleri

$9 \mathrm{~b}$. First two leaves ovate; subsequent leaves not lobed; seedlings with stellate hair

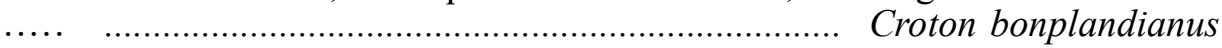

10a. First two leaves exstipulate $\ldots \ldots \ldots \ldots \ldots \ldots \ldots \ldots \ldots \ldots \ldots \ldots$

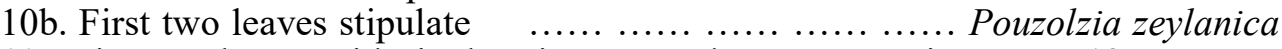

11a. First two leaves with single vein, camptodromous venation ..... 12

$11 \mathrm{~b}$. First two leaves with more than one vein, actinodromous venation ... 18 
12a. Margin of first two leaves entire ........................... 13

12b. Margin of first two leaves crenate or serrate . ................. 17

13a. First two leaves ovate with acute apex $\ldots \ldots \ldots \ldots \ldots \ldots \ldots \ldots \ldots \ldots$

13b. First two leaves lanceolate or elliptic with obtuse apex ........... 16

14a. (Para-) cotyledons linear with hyphodromous venation ... Achyranthes bidentata

14b. (Para-) cotyledons not linear with camptodromous venation $\ldots . . . \ldots . .15$

15a. (Para-) cotyledons oblong, without reddish tinge; base of first two leaves subrounded, surface corrugated ................... Heliotropium indicum

15b. (Para-) cotyledons ovate, with reddish tinge; base of first two leaves cuneate, surface not corrugated ........................ Ludwigia perennis

16a. (Para-) cotyledons lanceolate, apex obtuse; first two leaves lanceolate ...... Chenopodium album

16b. (Para-) cotyledons suborbicular, apex rounded; first two leaves elliptic ....... Euphorbia hirta

17a. First two leaves ovate, base subrounded, apex obtuse ... Anisomeles indica

17b. First two leaves elliptic-lanceolate, base cuneate, apex acute .. Leucas aspera

18a. (Para-) cotyledons sessile, base auriculate; first two leaves lanceolate, apex acute .............................................................. Cannabis sativa

18b. (Para-)cotyledons petiolate, base otherwise; first two leaves ovate, apex obtuse .. 19

19a. (Para-) cotyledons suborbicular, apex rounded ........... Ageratum conyzoides

19b. (Para-) cotyledons narrowly oblong, apex acute ......... Xanthium indicum

As per previous reports, cotyledon thickness has been considered as a conserved trait across the plant kingdom, but total seed mass did not show a strong signal as it varied considerably (Zanne et al. 2005). In present study, all species possess only paracotyledons, whereas seed size varied in most species by at least two orders of magnitude. Cotyledonary photosynthetic index (CPI, calculated as the inverse of cotyledon thickness) and seed mass were significantly negatively correlated (Figure $1 ; r^{2}=0.22, p d^{\prime \prime} 0.001$ ).

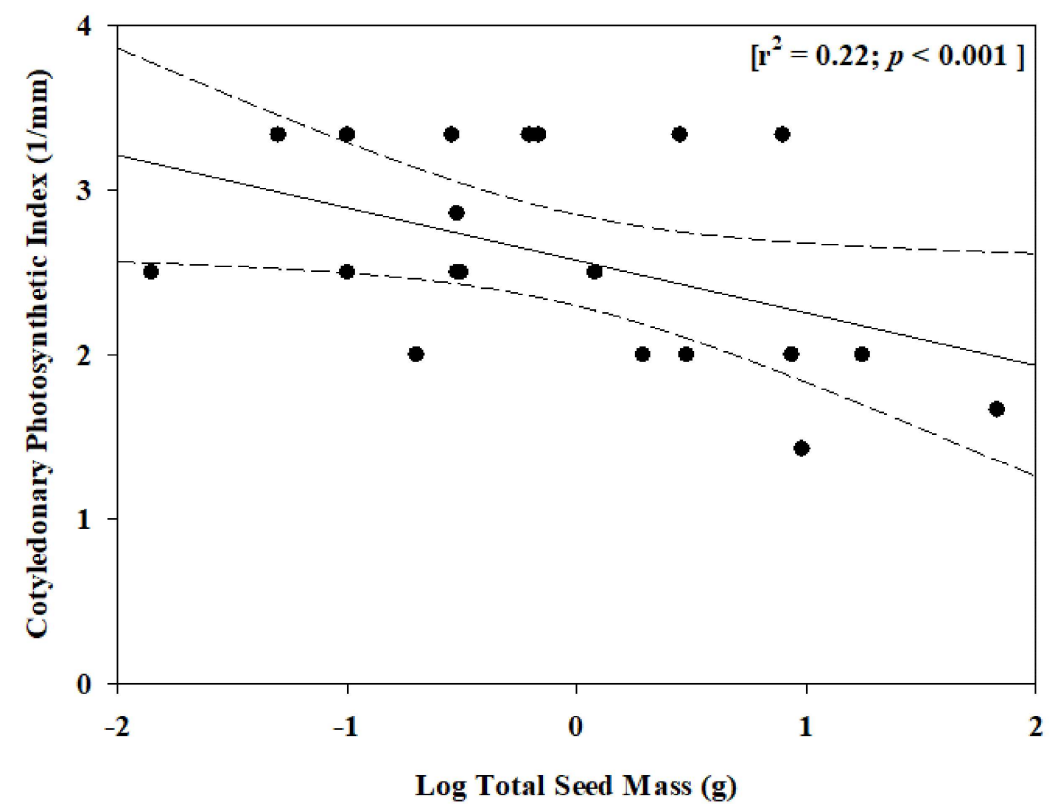

Figure 1. Relationship between total seed mass ( $\log _{10}$ - transformed) and cotyledonary photosynthetic index (= inverse of cotyledon thickness in $\mathrm{mm}$ ) for twenty weed species in Kaliachak II block, Malda, West Bengal $\left(r^{2}=0.22, p d " 0.001\right)$. 
The parameter CPI advocates an immediate more photosynthetic activity in light seeds than comparatively heavy seeds of these pioneer light demanding taxa. Light seeds are produced larger in number in annual weed than weeds having heavy seed mass. Further advantage of light seeded taxa involves in their wide distribution (Henry \& Westoby 2001) that triggers their survival in varied microhabitats of crop fields. Again taxa having comparatively heavy seed mass are usually distributed to surroundings of their mother plants. Their survival advantage depends on more resources in their seeds and hence, comparatively less CPI (Zanne et al. 2005). Besides seedlings from heavy seeds are better able to withstand many of the different stresses that seedlings face in natural environments, including competition from established vegetation, competition with other seedlings, prolonged period in deep shade under broad leaved crops, defoliation and burial under soil or litter (Moles \& Westoby 2004; Baraloto et al. 2005). Therefore, quantitative trait like thickness of paracotyledons (although not used in the key) for CPI analysis may be an additional parameter for distinction of taxa.

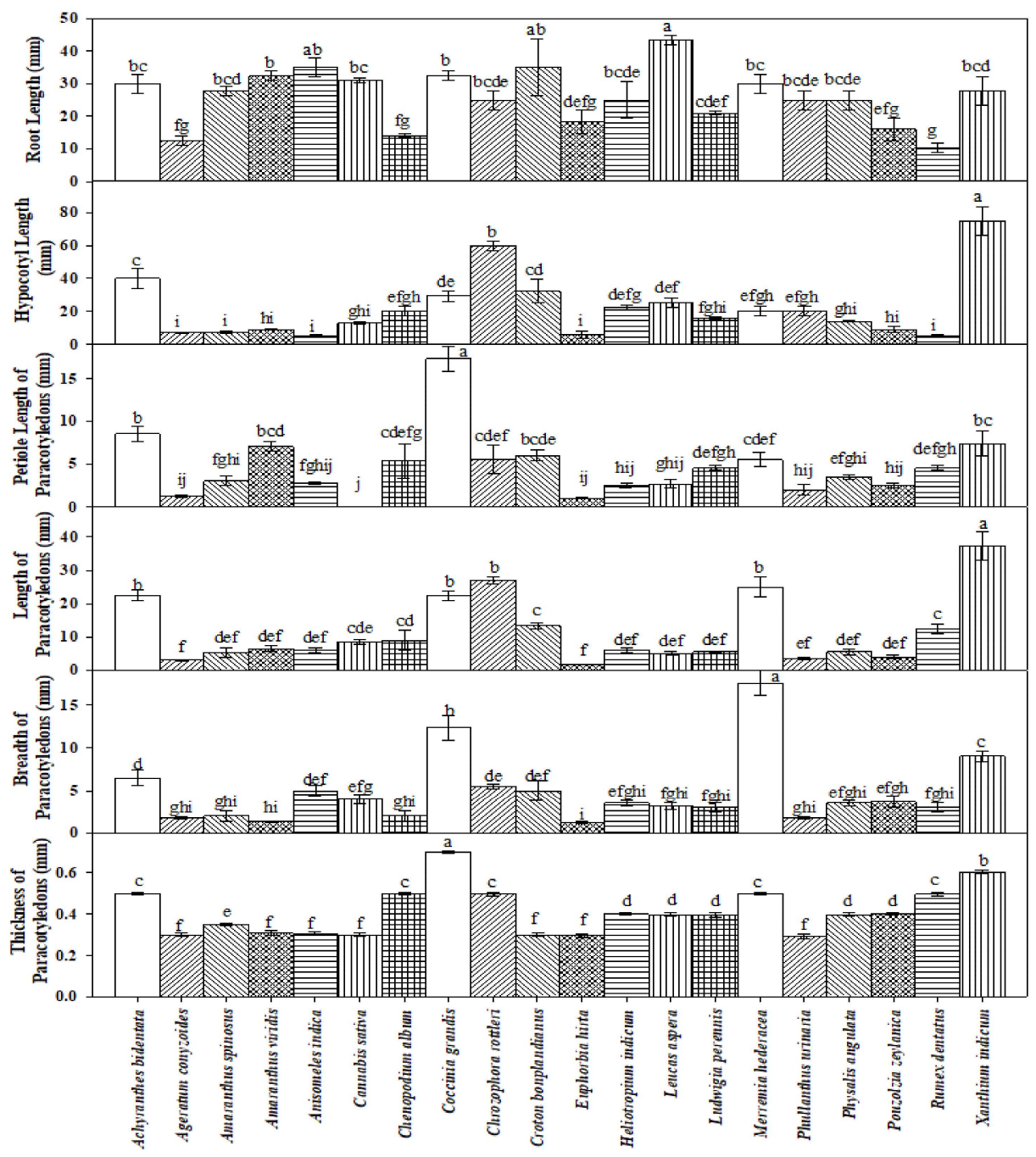

Figure 2. Analysis of different quantitative traits, i.e. - length of root, hypocotyls, petiole of paracotyledons, breadth and thickness of paracotyledons, occurring in twenty weed seedling found in and around agricultural fields of Kaliachak II block. Values represent mean $\pm \mathrm{SE}$. Bars showing different letters indicate partial significant differences according to Duncan's Multiple Range Test at $p$ d" 0.05 . 
ANOVA analysis (Figures $2 \& 3$ ) depicts significant differences in various quantitative traits like thickness, length-breadth of blade and length of paracotyledons; and hypocotyl length among Achyranthes bidentata, Chenopodium album, Chrozophora rottleri, Coccinia grandis, Merremia hederacea, Physalis minima, Rumex dentatus andXanthium indicum. While other twelve species show little variation of above traits. However, significant differences in root length characters has been observed among all twenty taxa.

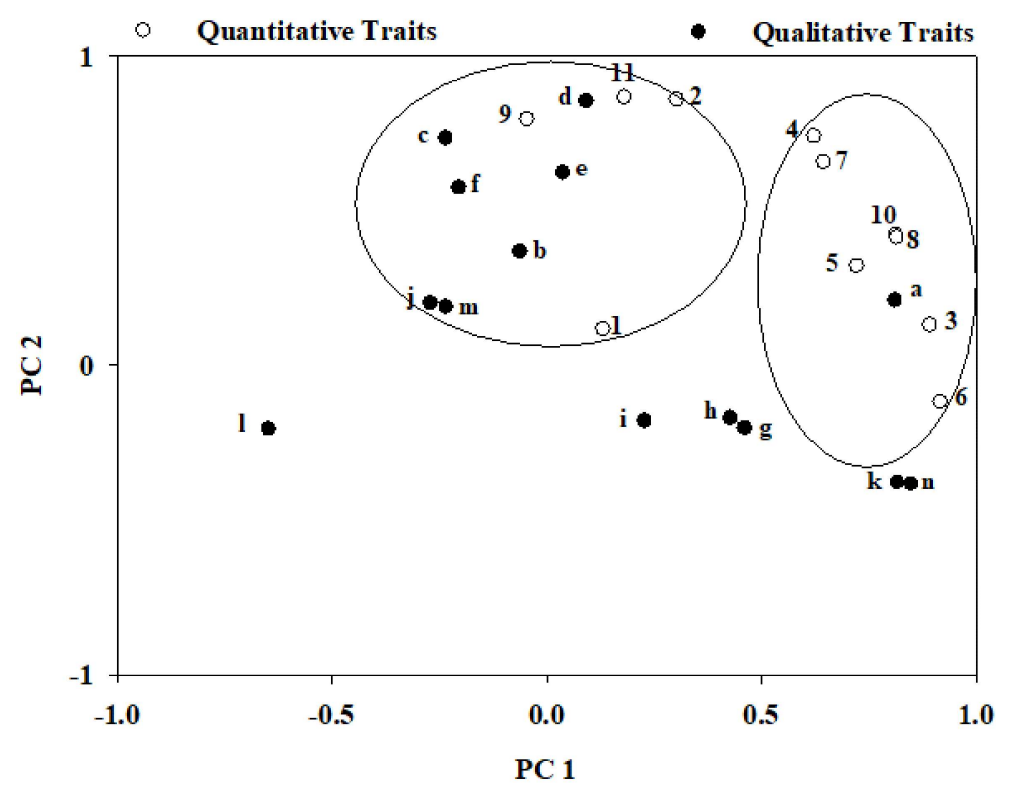

Figure 4. The principal component analysis (PCA) of qualitative and quantitative traits in twenty studied weed seedlings growing in and around agricultural fields of Kaliachak II block. The scatter plot of both the traits on the PC1 and PC2 side. Open (white circle) and closed (black circle) and symbols denote quantitative and qualitative traits, respectively. Each symbol represents the mean values for the PC scores of the three replicates of each parameter. For the convenience, the parameters are denoted by numbers and alphabets like - (1) root length, (2) hypocotyl length, (3) petiole length of paracotyledons, (4) length of paracotyledons, (5) breadth of paracotyledons, (6) petiole length of first two leaves, (7) length of first two leaves, (8) breadth of first two leaves, (9) first internode length, (10) thickness of paracotyledons, (11) seed weight; and (a) types of hypocotyls, (b) petiole types of paracotyledons, (c) shape of paracotyledons, (d) base of paracotyledons, (e) apex of paracotyledons, (f) venation types of paracotyledons, (g) phyllotaxy of first two leaves, (h) stipule types of first two leaves, (i) shape of first two leaves, (j) base of first two leaves, (k) apex of first two leaves, (l) margin of first two leaves, (m) venation pattern of first two leaves, (n) types of first internode.

Traits like seed weight, length of first internode, length, breadth and petiole length of first two leaves show variations among taxa like Achyranthes bidentata, Coccinia grandis, Chrozophora rottleri, Croton bonplandianus, Merremia hederacea and Xanthium indicumshow more significant differences in this connection.

Two circles showing grouping of traits have been emerged from PCA analysis (Figure 4). The small circle at right handed side, grouped majority of quantitative traits except one qualitative trait indicating interdependent nature of these traits, while the left handed large circle grouped both the traits more or less equally indicating their dependency. Few quantitative traits remain outside the groups. 


\section{CONCLUSION}

CPI quantifies the juvenile traits through the analysis of seed mass. ANOVA analyses significant differences of quantitative traits in many species. PCA advocates \pm independence of qualitative and quantitative traits. Thus numerical analysis of seedling traits through ANOVA and PCA direct the justification of identification of weeds in the form of artificial key.

Cotyledonary photosynthetic index (CPI) vs seed mass shows negative correlation. However, CPI manifests the variability of paracotyledon thickness which is distinctive for the identification of many crop field weeds at juvenile stage, if considered as conservative character in the key. ANOVA analysis demonstrates significant variation of various quantitative traits and, thus, consideration of these traits for distinction of some taxa in the artificial key is quite justified. Similarly, PCA analysis depicts the partial interdependence of qualitative and quantitative traits for the association of taxa in the same family following single primary lead as shown in artificial key. Thus, numerical analysis addresses the consideration of all kinds of seedling traits for taxonomic delimitation of taxa.

\section{Acknowledgements}

The authors are grateful to Prof. N.D. Paria, Department of Botany, University of Calcutta for his suggestions regarding research work in the field of seedling morphology. The authors are also thankful to Prof. Prasanta Dhair, Teacher-in-Charge, Balurghat College for providing laboratory and garden facilities.

\section{LITERATURE CITED}

Baraloto, C.; Forget, P.M. \& Goldberg, D.E. 2005. Seed mass, seedling size and neotropical tree seedling establishment. J. Ecol. 93: $1156-1166$.

Chomas, A.J.; Kells, J.J. \& Carey, J.B. 2001. Common weed seedlings of the North Central States. North Central Regional Extension Publication No. 607.

Das, A. \& Kamilya, P. 2014. Study of Seedling Diversity of some members of Leguminosae and Correlation of seed and seedling traits. J. Indian Bot. Soc. 93 (3 \& 4): 165 - 176.

Deb, D.K. \& Paria, N. 1986. Seedling morphology of some economic trees. Indian Agri. 30 (2): $133-142$.

De Vogel, E.F. 1980. Seedlings of dicotyledons. Structure, development, types, Descriptions of 150 woody Malesian taxa. Centre for Agricultural Publishing and Documentation (PUDOC), Wageningen, The Natherlands.

Fogliani, B.; Hopkins, H.C.F.; Bouraïma-Madjèbi, S. \& Medevielle, V. 2009. Morphological development of Geissois pruinosa (Cunoniaceae) from seed to adult stage and the expression of plesiomorphic characters in seedlings. Flora 204: 7-16.

Garwood, N.C. 2009. Seedlings of Barro Colorado Island and the neotropics. Comstock Pub., Ithaca.

Green, P.T. \& Juniper, P.A. 2004. Seed-seedling allometry in tropical rain forest trees: seed massrelated patterns of resource allocation and the 'reserve effect.' J. Ecol. 92: 397 - 408.

Henry, M.L. \& Westoby, M. 2001. Seed mass and seed nutrient content as predictors of seed output variation between species. Oikos 92: $479-490$.

Ibarra-Manríquez, G.; Ramos, M.M. \& Oyama, K. 2001. Seedling functional types in a lowland rain forest in Mexico. Amer. J. Bot. 88(10): 1801 - 1812.

Kamilya, P. \& Das, A. 2014. Seedling Characters for Correlation of some Species of Cohort Unisexuales (sensu Bentham and Hooker) in the Forest Patches of Dakshindinajpur, W.B. Pleione 8 (2): 416 - 426. 
Kamilya, P. \& Paria, N. 1993. Seedling morphology of some members of the Polygonaceae and its taxonomic implications. Rheedea 3(1): 29-34.

Kamilya, P. \& Paria, N. 1997. Seedling morphology of some members in the tribe Acahypheae (Euphorbiaceae). J. Indian Bot. Soc. 75: $1-6$.

Marwat, S.K.; Usman, K.; Khan, N.; Khan, M.U.; Khan, E.A.; Khan, M.A.\& Rehman, A.U. 2013. Weeds of wheat crop and their control strategies in Dera Ismail Khan district, Khyber Pakhtun Khwa, Pakistan. Amer. J. Pl. Sci. 4(1): 66 - 76.

Moles, A.T. \& Westoby, M. 2004. Seedling survival and seed size: a synthesis of the literature. J. Ecol. 92: $372-383$

Mukhopadhyay, S.; Bose, A.v\& Paria, N. 2013. Systematic value of seedling morphology of some members of the tribe Spermacoceae of Rubiaceae. Pleione 7(2): 357 - 365.

Naidu, A. \& Shah, G. 1978. Cotyledonary stomata and trichomes and their ontogeny in some genera of lamiaceae. Phyton (Horn Astria) 21: 137 - 152.

Paria, N. \& Kamilya, P. 1999. Seedling Morphology of some Indian Euphorbiaceae with reference to taxonomy and conservation of biodiversity, pp. 97-129. In: Biodiversity, Taxonomy and Ecology (Eds. Tandon RK and Singh P), Scientific Publication, India.

Paria, N.D.; Sanyal, S. \& Das (Ghosh), M. 2006. Correlation Coefficient of some character pairs in five tree seedlings of Leguminosae. J. Bot. Soc. Beng. 60(2): $134-139$.

Parkinson, H.; Mangold, J.\& Menalled, F. 2013. Weed seedling identification guide for Montana and the Northern Great Plains. Montana State University Extension, USA.

Rodrigues, R.S. \& Tozzi, A.M.G.A. 2008. Systematic relevance of seedling morphology inAcosmium,Guianodendron, andLeptolobium (Leguminosae, Papilionoideae). Brittonia 60: 287 - 296.

Sampathkumar, R. 1982. The cotyledonary leaves of some Convolvulaceae. Taxon 31(1): $53-56$.

Tillich, H.J. 2003. Seedling diversity in Araceae and its systematic implications. Feddes Repert. 114(7\&8): $454-487$.

Zanne, A.; Chapman, C. \& Kitajima, K. 2005. Evolutionary and ecological correlations of early seedling morphology in East African trees and shrubs. Amer. J. Bot. 92(6): 972 -978 . 